Journal of Teacher Education for Sustainability, vol. 22, no. 2, pp. 66-89, 2020

\title{
A Study on the Status of Sustainability Education among Iranian EFL Instructors: Developing a Glocalized Model
}

\author{
Zahra Tavakkoli and Naser Rashidi \\ Shiraz University, Shiraz, Iran
}

\begin{abstract}
In the Iranian education context where the concept of Sustainability Education is to a certain extent novel and fresh, one must first determine the state of Sustainability Education in education systems and specifically TEFL departments to discover EFL instructors' needs. This way, EFL instructors can be equipped with Sustainability Education competencies needed for transforming EFL education systems. Sustainability Education can be best implemented through language learning and specifically English learning compared with other subjects because language classes are the best sights for discussing sustainability issues. Additionally, the actualization of Sustainability Education in language classes can facilitate CLT and global citizenship operationalization. Having these in mind, the present study attempts to depict a clear picture of Sustainability Education among EFL instructors and provide education systems and policymakers with the necessary Sustainability Education competencies to equip teachers and help learners to feel and identify the relationship among sustainability issues such as culture, ecology, economy, power structures, and even their own families. The study was conducted using a Sustainability Education questionnaire developed by the researchers. The questionnaire was distributed among $150 \mathrm{EFL}$ instructors. The findings of the study reveal that EFL instructors experience an apparent lack of sustainability literacy. On the other hand, their level of implementation is better than literacy but still not much satisfactory. The important findings can bring about the transformation and modification of EFL teacher education and curriculum and will be highly advantageous regarding professional and ethical dimensions of education system.
\end{abstract}

Key words: sustainability, sustainability literacy, sustainability implementation, sustainability education

\section{Introduction}

The comprehensive construct of sustainability concerns intergenerational, evenhandedness, the interconnectedness of environment, economy, and social justice. It is a promising paradigm with a holistic view of human and non-human systems and involves transformative policies. On the other hand, education and sustainability are considered inextricable since sustainability will not come true in the absence of education (Onwueme \& 
Borasi, 2007). As a result, the term "Sustainability Education (SE)" has emerged and been discussed under the labels of Education for Sustainability (EFS) and Education for Sustainable Development (ESD).

Sustainability Education (SE) or Education for Sustainable Development aims at incorporating the philosophies, ethics, and practices of Sustainable Development (SD) into all education facets (Redman, 2013; Heasly et al., 2020). It is a movement in all subject areas such as English, which tries to make people, societies, and governments gain a great understanding of environmental, economic, and social situations and integrate it into their contemplation of humanity (Vincent, Bunn, \& Stevens, 2013). Implementation of sustainability is not imaginable without education since education has a major role in enhancing learners' cognitive and affective dimensions, which can then bring about knowledgeable, skillful, and healthy residents who are mindful and inspired to live more sustainably and safeguard future generations (Biasutti, De Baz, \& Alshawa, 2016; Carban \& Fisher, 2017). Sustainability Education is, in fact, an attempt towards behavior transformation and re-orientation. Sustainability Education is a socio-psychological multidisciplinary approach that seeks effective ways to achieve individual and social well-being. It will not be achieved without the two main factors of literacy and implementation (Kabadayi, 2016). In the area of Sustainability Education, environmental, social, and economic phases of sustainable development need to be unified to develop learners' sustainability consciousness and literacy, which encompasses their knowingness, attitudes, and behavior and leads to behavioral change through sustainability implementation (Carban \& Fisher, 2017).

Sustainability Education is applicable to all subjects such as physics, mathematics, and English. This way, different SE versions, for instance, EFL SE and psychology SE, will be presented. The main burden in Sustainability Education is on teachers' shoulders since they are believed to be the receptacles of education. As learners are the mirrors of their teachers, these are teachers who should help learners cultivate the special knowledge and skills required for sustainable development, which is a multifaceted issue and needs a great deal of training. Wals (2011) believed that for learners to develop sustainably, they should be able to make decisions sustainably connected with teachers' literacy and teaching methods (Abdulwali, Alshmrani, \& Almufti, 2017; Besong \& Holland, 2015).

Teachers as the main agents of sustainability development in education should be not only teachers but also constant learners and researchers. This highlights the interwoven relationship between professional development and sustainability literacy. Since sustainability is not an exclusively environmental or economic issue, it can be best implemented in English classes through teachers teaching not only language but also culture and lifestyle (Zeeshan, 2017). Therefore, English classes can be the best site for SE execution in Iran because the humanities and culture, in particular, are identified as core drivers of sustainability (Fry \& Wei, 2015). Cultural approaches to sustainability are directly related to lifestyle, and the discussion and debate sessions in English classes provide teachers with the best opportunity to discuss sustainability issues with learners. Concerning Zeeshan's findings, EFL SE can be considered one of the most important versions of SE in Iran, which can lead to worthwhile outcomes since language and communicative and cross-cultural competence are treated as the main factors of sustainability actualization (Human Resources Development, 2012; Committee for Global Human Resources Development, 2012).

From another point of view, Sustainability Education is believed to be interwoven with the two concepts of Global Citizenship and Identity (Committee for Global Human 
Resources Development, 2012). Moreover, English language teaching is considered a key to fostering global citizenship, identity achievement and an attitude towards sustainable development (Basarir, 2017; Commission on the Development of Foreign Language Proficiency, 2011). The introduction of these concepts into the EFL context can trigger the whole context, including teachers and learners, in a way to help learners identify as global citizens who have an achieved sense of identity and can ensure future development (Tsukamoto, 2014). In fact, Tsukamoto stated that implementation of Sustainability Education in English language teaching could facilitate the implementation of Communicative Language Teaching (CLT) in EFL settings.

A comprehensive view of SE is believed to be the main part of a healthy, highquality education (Fry \& Wei, 2015). Up until now, the components of SE have not been introduced as a whole to provide a foundation for further research. As a result, the researchers in the present study made an attempt to gather the main components through a careful review of the related literature (Andic \& Vorkapic, 2017; Brundiers \& Wiek, 2017; Demirci \& Teksoz, 2017; Frisk \& Larson, 2011; Nolet, 2009; Rashidi \& Meihami, 2017; Reunamo \& Suomela, 2013; Uitto \& Saloranta, 2017; Wen \& Wu, 2017; Zeeshan, 2017) and UNESCO Sustainability development elements, which led to the development of a comprehensive model of SE (Figure 1).

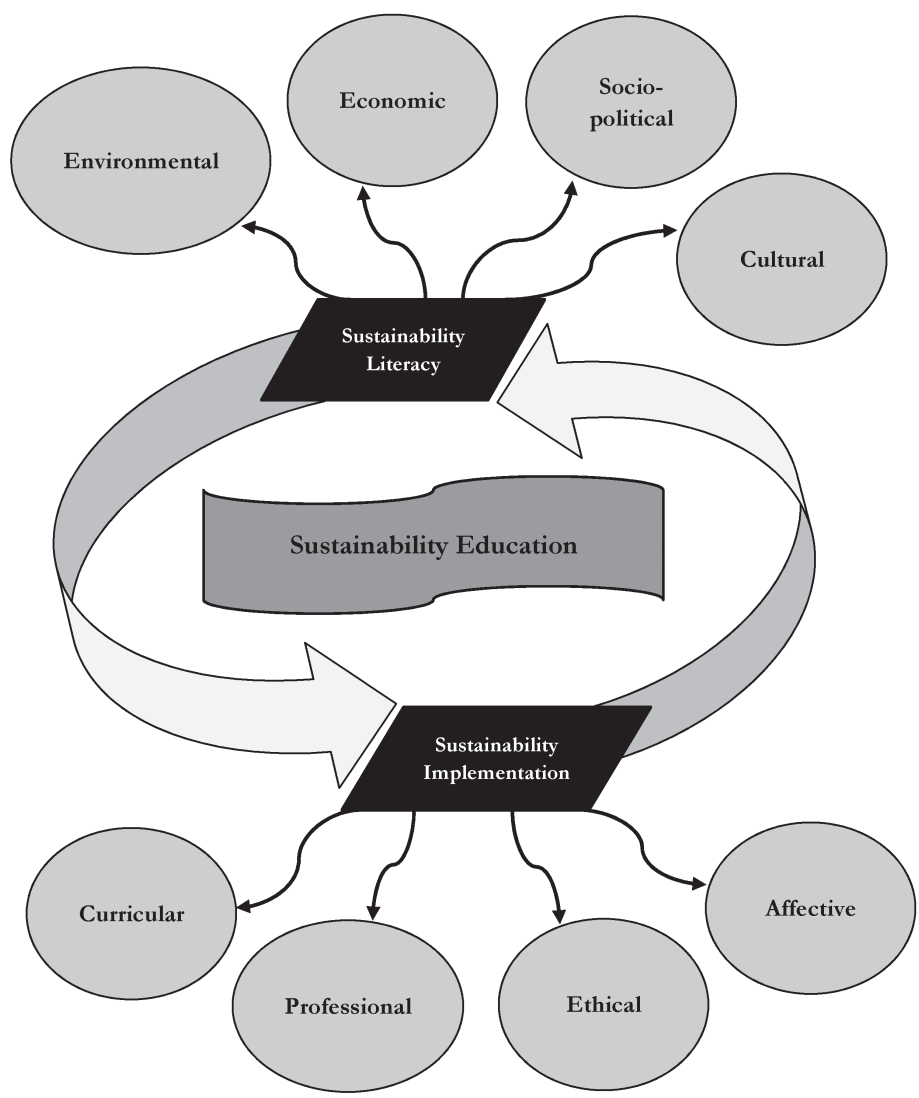

Figure 1. The comprehensive model of Sustainability Education developed based on literature and UNESCO sustainability development elements 


\section{Background}

Reviewing the literature reveals that sustainability and sustainable development are used interchangeably in numerous studies, yet some investigators believe these two complex concepts have to be clearly cut. Sustainability Education or Education for Sustainability was for the first time officially stated by UNESCO in 1997 as a movement toward a better future. UNESCO report was an attempt to introduce SE as the main weapon against environmental, social, and economic issues. Subsequently, the importance of sustainability implementation in education was emphasized time after time in numerous studies (Brundiers \& Wiek, 2017; Corcoran, Osano, Weakland, \& Hollingshead, 2009; Demirci \& Teksoz, 2017; Frisk, 2011; Redman, 2013; Reunamo \& Suomela, 2013; Samari, 2012; Stewart, 2010; Uitto \& Saloranta, 2017). Some of these researchers (Corcoran, Osano, Weakland, \& Hollingshead, 2009; Reunamo \& Suomela, 2013) mainly focused on SE implementation in children's education and some others (Brundiers \& Wiek, 2017; Stewart, 2010) focused on higher education. Afterward, some researchers, though not many, went beyond sustainability implementation in education and dealt with SE actualization in different areas such as foreign language teaching (Wen \& Wu, 2017; Zeeshan, 2017).

Anyolo, Karkkainen, and Keinonen (2018) investigated teachers' perceptions and practices regarding sustainability literacy and implementation through a qualitativeexplorative study design. The following results were obtained: 1) The teachers were familiar with the concept of sustainability without undergoing training; 2) All the teachers incorporated SE into their subjects and curriculum without prior preparation; 3) The teachers were able to respond to sustainability challenges without familiarity with sustainability components; 4) The teachers confessed to the universal need for literate, knowledgeable teachers in sustainability; 5) There was a connection between teachers' field of study and their preferences and power points.

Some teachers' experiences of practices in SE were probed into by Sund in 2016. The teachers in Sund's study strongly looked with favor on political aspects of sustainability since they believed that power structures and relations were of considerable importance in sustainability development. They also pointed to the seriousness of the ethical dimensions and coined the term "ethico-political" to show the integration of these two areas to develop learners' empowerment. Sund concluded that some aspects of sustainability such as political, historical, and epistemological were field-specific. The ethical and affective dimensions, on the other hand, were not. This means that how a teacher weighs a dimension depends on the teacher's field of study.

Zeeshan (2017) emphasized the importance of ESD promotion through English language teaching. His ideas were in line with those of UNESCO (2005) regarding the vital role of universities in the expansion of sustainability modus operandi. The good fortune of the society is resultant from sustainability literacy and implementation, which will not come true in the absence of well-informed, educated English teachers. The researcher further maintained that SE and ELT seemed alien at first glance since English language teachers felt that they were supposed to teach merely a language, i.e., vocabulary, grammar, and communication skills. This can be why English language teachers' central role has been neglected so far, although some researchers have depicted a clear picture of the close connection between SE and EFL (Jacobs \& Cates, 1999). Most English teachers participating in the study believed that the insufficiency of teacher training, 
quality of curriculum materials, and support from the administration were the first three noticed obstacles to sustainability development followed by lack of infrastructure and equipment and access to teaching resources. The study also indicated literacy as a pre-requisite for implementation. The English teachers did not know what information should be included in lectures, videos, presentations, and discussions.

Andic and Vorkapic (2017) used Juarez-Najera's socio-psychological model of sustainable behavior (2010) to depict a clear picture of teacher students' awareness of environmental problems and how to attribute responsibility for environmental/ sustainability problems. Furthermore, the authors claimed that systemic education as opposed to linear education was a must for change towards sustainable behavior. The values of the systemic and linear models are totally different and lead to two different education systems. At the heart of a systemic model, there are awareness, collaboration, participation, care and quality, which bring about an all-round education system that draws a circular but not a hierarchical structure that reforms the pattern of society based on collective growth, personalization, transdisciplinary approach, network, responsibility, and collaboration and finally develops sustainability (Dominici \& Peruccio, 2016).

Gholami and Qurbanzada (2016) studied TEFL key stakeholders' attitudes towards teacher education programs. They maintained the importance of sustainable development in education and teacher education since sustainability in education was the gate to behavior change. The stakeholders believed that sustainability awareness acted as a facilitator of sustainability implementation and both were the necessary characteristics of efficient teaching in this era.

The effectiveness of EFL SE lies in its multi-dimensional platform. EFL SE is a means to accomplish not only sustainability goals but also linguistic ones. Regarding sustainability goals, EFL SE has enormous potential to raise sustainability consciousness and command of language (Zeeshan, 2017). EFL SE lends itself to Education for Global Citizenship (EGC) and can be the driving force behind personality and linguistic development (Ban, 2012). As a matter of fact, EFL SE can be discussed under the umbrella term "EGC" since EGC covers the core principles of both EFL and SE. It considers local and global issues, cultural and cross-cultural differences, acquiring a working knowledge of English as a lingua franca and developing communicative language proficiency (Ishimori, 2010).

\section{Research Methods}

The present study has mainly investigated if Iranian instructors have the knowledge, skills and tenets that enlighten the learners' mental models and day-to-day behaviors and help them engage in critical thinking, problem-solving, and decision making. In fact, depicting the overall status of SE in the Iranian EFL context and investigating the existence of a certain pattern among SE components have been the ultimate goal of the present study. As each phase of the study has its own goals and sub-goals and all are channels towards the final goal of the research, i.e., development of a relatively comprehensive glocalized model of EFL SE, the following research questions have been raised:

1. How competent are EFL instructors regarding their SE literacy?

2. In which dimensions of Sustainability Literacy are the instructors more competent? 
3. How often is SE implemented in EFL classes?

4. Which dimensions are implemented more often in EFL classes?

5. What is the overall status of SE in the Iranian EFL context?

6. What are the components of the glocalized SE model?

\section{Participants}

The participants in the study were 150 EFL instructors at Shiraz University, Shiraz Islamic Azad University, Zand University, Apadana University, Pasargad University, Persian Gulf University, Tehran University, and Yazd University. They were selected via convenience and snowball sampling. The instructors, chosen for accessibility reasons, were from the same education level, but different age, gender and educational and experiential background.

\section{Instrument}

The main instrument of the study was an SE questionnaire developed by the researchers. For the development of the questionnaire, the researchers first prepared a list of global features and elements of Sustainability Development recommended by UNESCO and also extracted from attainable literature. For the global features to be locally practical, the researchers asked the officials at relevant organizations, such as Department of Environmental Protection, Planning and Budget Organization, Agricultural Jihad Organization, Department of Culture and Islamic Guidance, to check the locally associated features. The questionnaire items were then developed based on these features. The list of the items was checked and rechecked by SE expertise for the content validity. In the next step, the rating scales and instructions were designed and the items were first analysed and then based on the results of the analysis they were revised. The final version of the questionnaire was administered to a group of 200 EFL instructors for its reliability and validity, which were estimated through Cronbach's Alpha (CA) and Confirmatory Factor Analysis (CFA), respectively.

\section{Reliability}

For the confirmation of reliability, CA of each item was estimated separately to find the items which were supposed to be eliminated. CA for all the items in the first part of the questionnaire and the total CA for sustainability literacy were estimated (see the results in Table 1). The total alpha reliability coefficient for sustainability literacy was equal to 0.943 , which confirmed the reliability of the first part of the questionnaire since it was above 0.7 . 
Table 1

Reliability of Sustainability Literacy Questionnaire

\begin{tabular}{ccccc}
\hline Item number & $\begin{array}{c}\text { Cronbach's Alpha } \\
\text { if Item Deleted }\end{array}$ & Item number & $\begin{array}{c}\text { Cronbach's Alpha } \\
\text { if Item Deleted }\end{array}$ & $\begin{array}{c}\text { Total } \\
\text { Cronbach's Alpha }\end{array}$ \\
\hline s1 & .941 & $\mathrm{~s} 14$ & .941 & .943 \\
\hline $\mathrm{s} 2$ & .940 & $\mathrm{~s} 15$ & .941 & \\
\hline $\mathrm{s} 3$ & .941 & $\mathrm{~s} 16$ & .940 & .941 \\
\hline $\mathrm{s} 4$ & .941 & $\mathrm{~s} 17$ & .941 \\
\hline $\mathrm{s} 5$ & .942 & $\mathrm{~s} 18$ & .944 \\
\hline $\mathrm{s} 6$ & .940 & $\mathrm{~s} 19$ & .942 \\
\hline $\mathrm{s} 8$ & .940 & $\mathrm{~s} 20$ & .940 \\
\hline $\mathrm{s} 9$ & .942 & $\mathrm{~s} 21$ & .941 \\
\hline $\mathrm{s} 10$ & .942 & $\mathrm{~s} 22$ & .941 \\
\hline $\mathrm{s} 11$ & .940 & $\mathrm{~s} 23$ & .942 \\
\hline $\mathrm{s} 13$ & .942 & $\mathrm{~s} 24$ & .940 \\
\hline & .941 & $\mathrm{~s} 25$ & .941 \\
\hline
\end{tabular}

CA for all the items in the second part of the questionnaire and the total CA for sustainability implementation were estimated (see the results in Table 2). As shown in Table 2, the total alpha reliability coefficient for sustainability implementation was equal to 0.947 , which confirmed the reliability of the second part of the questionnaire since it was above 0.7 .

Table 2

Reliability of Sustainability Implementation Questionnaire

\begin{tabular}{|c|c|c|c|c|}
\hline Item number & $\begin{array}{l}\text { Cronbach's Alpha } \\
\text { if Item Deleted }\end{array}$ & Item number & $\begin{array}{l}\text { Cronbach's Alpha } \\
\text { if Item Deleted }\end{array}$ & $\begin{array}{c}\text { Total } \\
\text { Cronbach's Alpha }\end{array}$ \\
\hline $\mathrm{s} 28$ & .975 & s47 & .973 & .943 \\
\hline s29 & .976 & s48 & .972 & \\
\hline s30 & .974 & s49 & .973 & \\
\hline s31 & .973 & s50 & .973 & \\
\hline s32 & .973 & s51 & .972 & \\
\hline s33 & .973 & s52 & .973 & \\
\hline s34 & .973 & s53 & .973 & \\
\hline s35 & .974 & s54 & .973 & \\
\hline s36 & .974 & s55 & .973 & \\
\hline s37 & .974 & s56 & .972 & \\
\hline s38 & .973 & s57 & .973 & \\
\hline s39 & .973 & s58 & .973 & \\
\hline s40 & .973 & s59 & .973 & \\
\hline s41 & .974 & s60 & .973 & \\
\hline s42 & .974 & s61 & .973 & \\
\hline s43 & .974 & $\mathrm{~s} 62$ & .972 & \\
\hline s44 & .974 & s63 & .973 & \\
\hline s45 & .972 & s64 & .973 & \\
\hline s46 & .973 & s65 & .973 & \\
\hline
\end{tabular}




\section{Validity}

To confirm the construct validity of the questionnaire, CFA, which is a quantitative data analysis method that belongs to the family of structural equation modeling (SEM) techniques, was used. CFA allowed for the assessment of fit between the observed data and an a priori conceptualized, theoretically grounded model that specifies the hypothesized causal relations between latent factors and their observed indicator variables. The CFA results for sustainability literacy are shown in Table 3 and the relationship between factors is depicted in Figure 2. As shown in Table 3, p-value for all the items is below .005 which proves the validity of the items in the first part of the questionnaire.

Table 3

\section{CFA of Sustainability Literacy Variables}

\begin{tabular}{|c|c|c|c|c|}
\hline Item number & Item type & Estimate & C.R. & $\mathrm{P}$ \\
\hline $\mathrm{q} 1$ & environmental & 1.000 & & \\
\hline $\mathrm{q} 2$ & environmental & 1.329 & 3.614 & $* * *$ \\
\hline $\mathrm{q} 3$ & environmental & 1.355 & 3.240 & .001 \\
\hline $\mathrm{q} 4$ & environmental & 1.130 & 3.655 & $\because * *$ \\
\hline q9 & economic & 1.000 & & \\
\hline $\mathrm{q} 10$ & economic & 1.402 & 2.606 & .009 \\
\hline q11 & economic & 1.268 & 2.392 & .017 \\
\hline q12 & economic & 1.434 & 2.519 & .012 \\
\hline q24 & Cultural & 1.000 & & \\
\hline $\mathrm{q} 25$ & Cultural & 1.491 & 1.982 & .042 \\
\hline q26 & Cultural & 2.082 & 1.961 & .045 \\
\hline $\mathrm{q} 27$ & Cultural & 2.007 & 2.608 & .008 \\
\hline q16 & sociopolitical & 1.000 & & \\
\hline q17 & sociopolitical & .940 & 3.867 & $* * *$ \\
\hline q18 & sociopolitical & .767 & 3.636 & $* * *$ \\
\hline q19 & sociopolitical & .496 & 2.030 & .042 \\
\hline $\mathrm{q} 5$ & environmental & .965 & 2.802 & .005 \\
\hline s6 & environmental & 1.250 & 3.859 & $* * *$ \\
\hline $\mathrm{q} 7$ & environmental & 1.337 & 3.595 & $\because * *$ \\
\hline $\mathrm{q} 8$ & environmental & 1.040 & 2.595 & .009 \\
\hline q13 & economic & 1.562 & 2.697 & .007 \\
\hline q14 & economic & 1.240 & 2.360 & .018 \\
\hline q15 & economic & 1.344 & 2.509 & .012 \\
\hline $\mathrm{q} 20$ & sociopolitical & .715 & 2.726 & .006 \\
\hline $\mathrm{q} 21$ & sociopolitical & .927 & 4.227 & $* * *$ \\
\hline $\mathrm{q} 22$ & sociopolitical & .783 & 3.777 & $\approx * *$ \\
\hline q23 & sociopolitical & .777 & 3.492 & $* * *$ \\
\hline
\end{tabular}




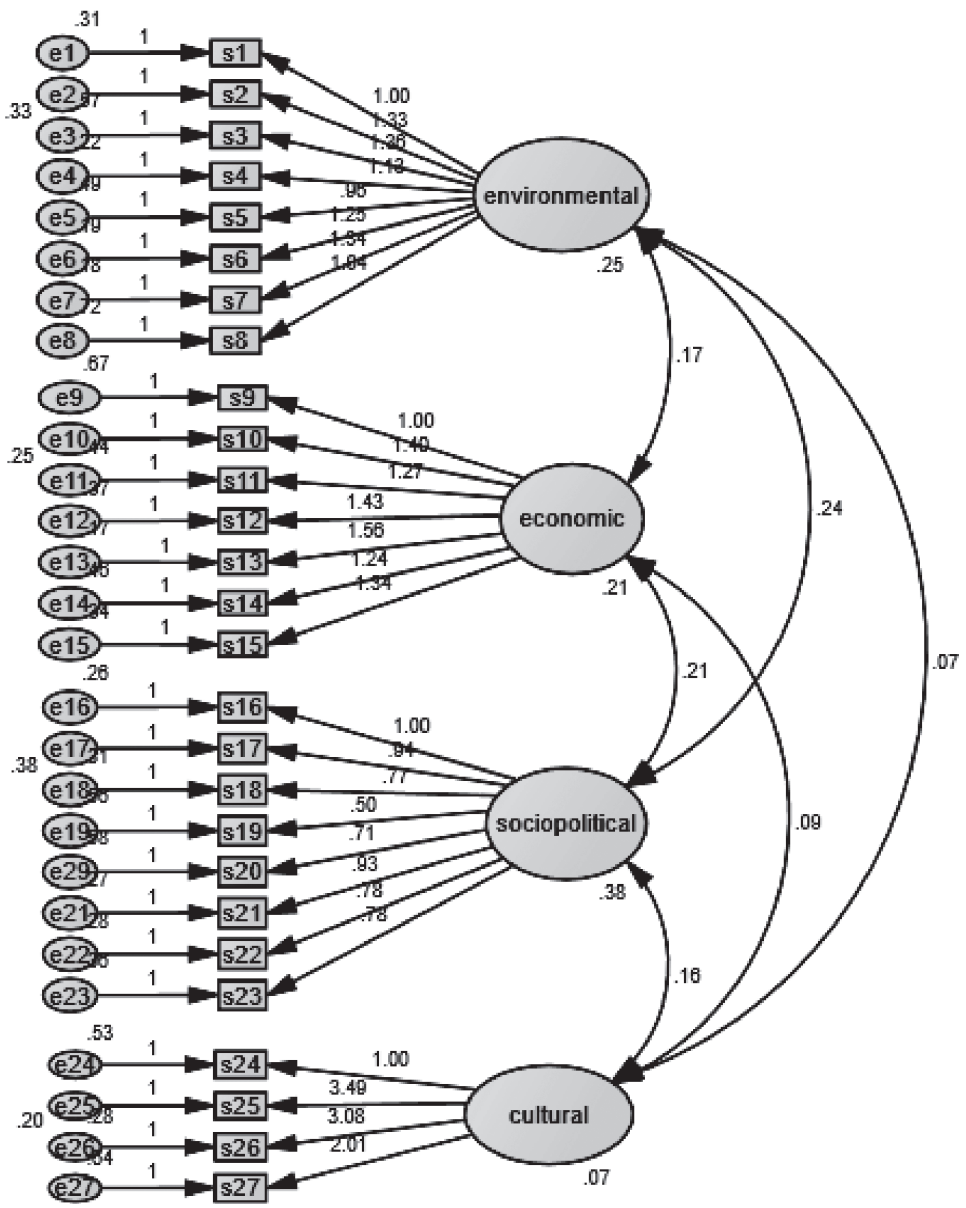

Figure 2. The relationship between sustainability literacy variables

The results of CFA for sustainability implementation are shown in Table 4 and the relationship between factors is depicted in Figure 3. As shown in Table 4, p-value for all the items is below .005 , which proves the validity of the items in the second part of the questionnaire.

Table 4

CFA of Sustainability Implementation Variables

\begin{tabular}{clccc}
\hline Item number & Item type & Estimate & C.R. & P \\
\hline $\mathrm{q} 30$ & Curricular & 1.000 & & \\
\hline $\mathrm{q} 29$ & Curricular & .798 & 6.289 & $* * *$ \\
\hline $\mathrm{q} 28$ & Curricular & 1.017 & 7.045 & $* * *$ \\
\hline $\mathrm{q} 49$ & professional & 1.000 & & \\
\hline $\mathrm{q} 48$ & professional & .909 & 4.911 & $* * *$ \\
\hline $\mathrm{q} 47$ & professional & .790 & 4.241 & $* * *$ \\
\hline $\mathrm{q} 46$ & professional & .990 & 4.969 & $* * *$ \\
\hline
\end{tabular}


Continuation of Table 4

\begin{tabular}{|c|c|c|c|c|}
\hline $\mathrm{q} 45$ & professional & 1.085 & 4.892 & $* * *$ \\
\hline q44 & professional & 1.021 & 4.904 & $* * *$ \\
\hline q43 & professional & 1.091 & 5.328 & $* * *$ \\
\hline $\mathrm{q} 42$ & professional & .924 & 4.667 & $* * *$ \\
\hline q41 & professional & .846 & 4.569 & $* * *$ \\
\hline $\mathrm{q} 40$ & professional & 1.270 & 5.569 & $* * *$ \\
\hline q39 & professional & 1.202 & 5.474 & $* * *$ \\
\hline q38 & professional & .723 & 4.081 & $* * *$ \\
\hline q37 & professional & .709 & 4.059 & $* * *$ \\
\hline q36 & professional & .868 & 4.641 & $* * *$ \\
\hline $\mathrm{q} 35$ & professional & .592 & 3.546 & $* * *$ \\
\hline q34 & professional & 1.106 & 5.202 & $* * *$ \\
\hline q33 & professional & .817 & 4.484 & $* * *$ \\
\hline q32 & professional & .986 & 4.778 & $* * *$ \\
\hline q31 & professional & 1.002 & 4.730 & $* * *$ \\
\hline $\mathrm{q} 58$ & Ethical & 1.000 & & \\
\hline q57 & Ethical & 1.145 & 6.074 & $* * *$ \\
\hline q56 & Ethical & 1.364 & 6.596 & $* * *$ \\
\hline $\mathrm{q} 55$ & Ethical & 1.109 & 6.036 & $* * *$ \\
\hline q54 & Ethical & 1.360 & 6.542 & $* * *$ \\
\hline $\mathrm{q} 53$ & Ethical & .859 & 5.056 & $* * *$ \\
\hline q52 & Ethical & .824 & 4.904 & $* * *$ \\
\hline q51 & Ethical & .936 & 5.499 & $* * *$ \\
\hline q50 & Ethical & 1.080 & 5.866 & $* * *$ \\
\hline q59 & Affective & 1.000 & & \\
\hline $\mathrm{q} 60$ & Affective & .692 & 5.355 & $* * *$ \\
\hline $\mathrm{q} 61$ & Affective & 1.284 & 10.132 & $* * *$ \\
\hline q62 & Affective & 1.302 & 10.097 & $* * *$ \\
\hline q63 & Affective & .566 & 4.418 & $* * *$ \\
\hline q64 & Affective & 1.056 & 8.172 & $* * *$ \\
\hline q65 & Affective & 1.008 & 7.146 & $* * *$ \\
\hline
\end{tabular}




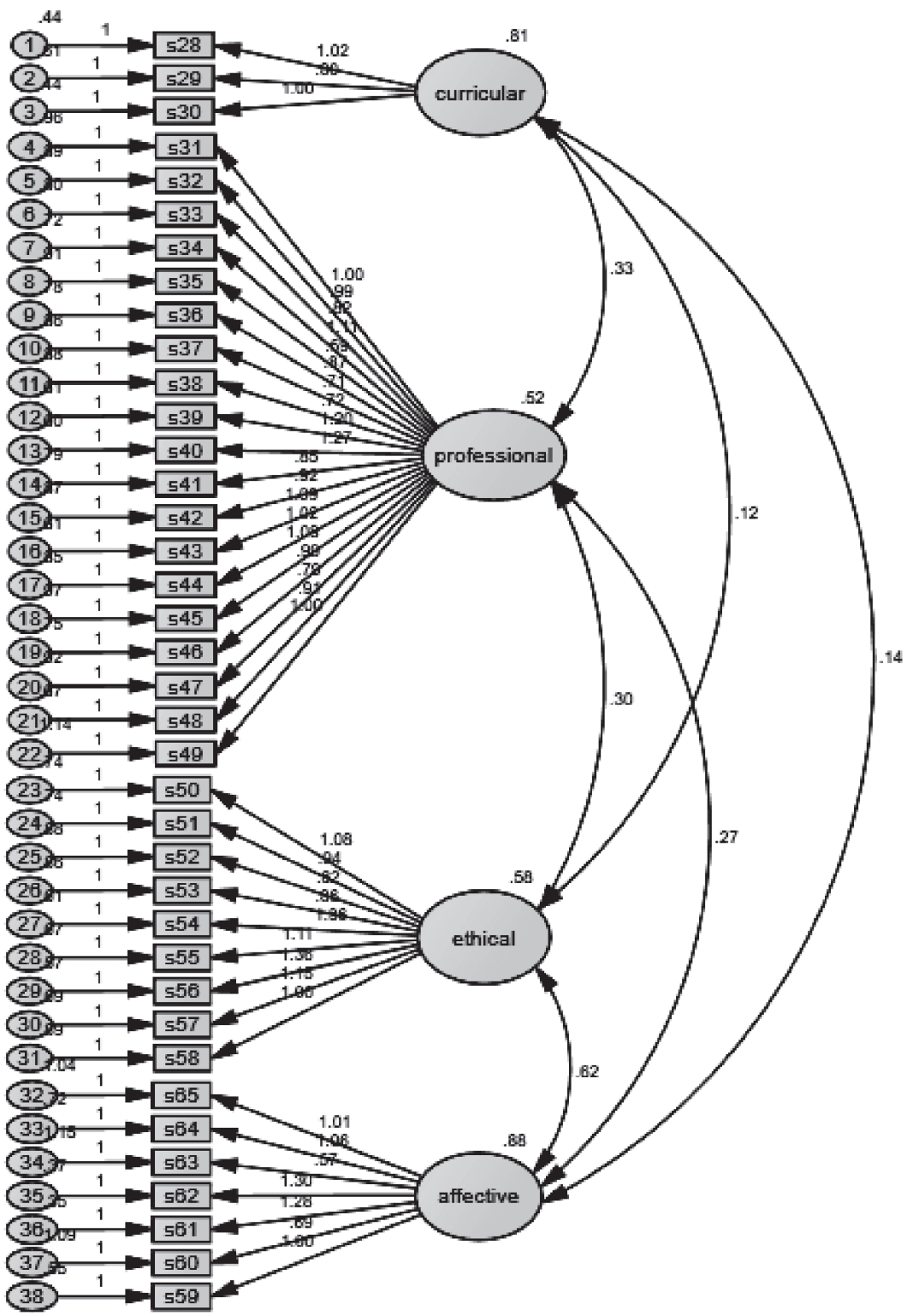

Figure 3. The relationship between sustainability implementation variables

According to Nolet (2009), in order to check if Iranian EFL instructors are literate in sustainability or not, they were asked if they "knew things associated with sustainability, if they were disposed to think or solve problems in ways associated with sustainability, and if they behaved in ways consistent with sustainability" regarding the four different sustainability dimensions (ecological, economic, social and cultural) (p. 429). Then, they were asked how often they implemented SE in their classes. The frequency of different activities was rated according to a five-point Likert scale: 5 = very often, $4=$ rather often, 3 = sometimes, 2 = rather seldom, 1 = very seldom. The teachers' perceptions 
of their competence in SE were assessed using five items with which the teachers could rate their responses according to a five-point Likert scale: $1=$ very poor, $2=$ rather poor, 3 = satisfactory, 4 = rather good, 5 = very good. The questionnaire also provided us with information about different dimensions of SE separately.

\section{Data Collection Procedure}

The data related to instructors were gathered using the SE questionnaire. The questionnaire was administered both in person and online to let the target participants have a choice over the completion process. Before the distribution of the questionnaire, the researchers contacted the instructors at each university and got permission for the process. The instructors were also asked to distribute the questionnaire to as many EFL instructors as possible.

\section{Data Analysis Procedure}

For data analysis, different tests and analysis procedures were used. First of all, descriptive statistics and means comparison graphs were used to discover the overall status of sustainability literacy, sustainability implementation, and sub-divisions. Then, to check the normality of distribution, the Kolmogorov-Smirnov test was used to decide whether the sample came from the population with a specific distribution. Since normality was accepted, a one-sample t-test was used as a tool to compare the sample mean with the hypothesized mean to determine whether the two means were significantly different or not. These tests were used to gain insights into EFL instructors' level of competence and implementation.

\section{Results}

\section{Descriptive Statistics}

Using descriptive statistics, the sustainability literacy and implementation level of EFL instructors were revealed. The descriptive statistics results demonstrated that EFL instructors' sustainability implementation was in a better condition compared to their sustainability literacy. Figure 4 shows that EFL instructors' sustainability literacy is less than 3 (2.40), while their sustainability implementation is over 3 (3.28). Although the sustainability implementation of EFL instructors is above the mean score, there is not a large gap between sustainability literacy and implementation. The mean scores of both sustainability literacy and implementation confirm that EFL instructors are not in a satisfactory position in terms of sustainability education with the mean score of 2.83 as shown in Figure 5. 


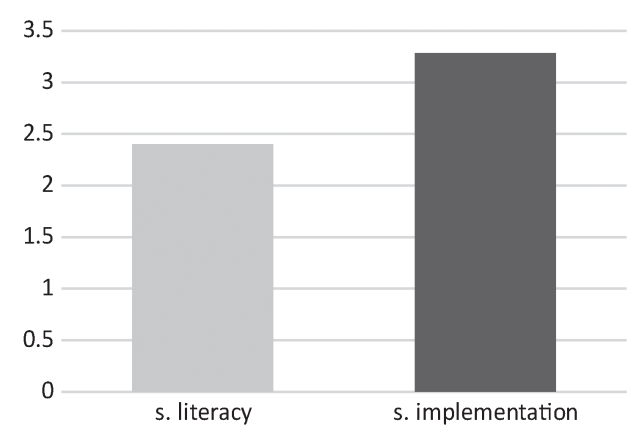

Figure 4. Means comparison: sustainability literacy versus sustainability implementation

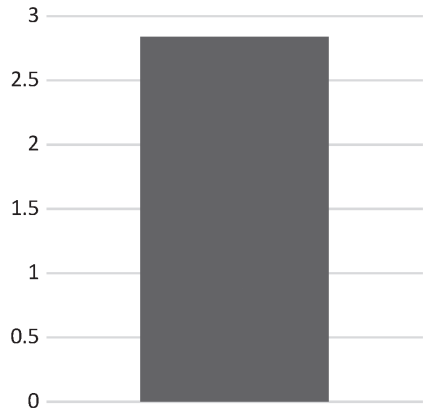

Figure 5. Mean score of Sustainability Education

Mean and standard deviation estimates for sustainability literacy sub-divisions revealed worthwhile information regarding its four main dimensions, i.e., environmental, economic, socio-political, and cultural. The results showed that EFL instructors were the least literate in terms of environmental and economic sustainability and the most literate in terms of cultural and socio-political sustainability compared with the total medium score, which was 3. In fact, EFL instructors confirmed that they were culturally literate but not environmentally literate. More details about sustainability literacy descriptive statistics can be seen in Table 1. As shown in Table 5, the mean scores for the environmental and economic dimensions are below the medium (1.66 and 1.89) and the mean scores for the socio-political and cultural dimensions are above the medium (3.14 and 3.29). The bar graphs also confirm this revelation (Figure 6). The attained scores imply that the instructors' socio-political and cultural literacy is in a better condition compared to their environmental and economic literacy.

Table 5

Descriptive Statistics of the Participating Instructors' Sustainability Literacy

\begin{tabular}{lccccc}
\hline & environmental & economic & sociopolitical & cultural & s. literacy \\
\hline Mean & 1.6624 & 1.8907 & 3.1485 & 3.2917 & 2.4019 \\
\hline Std. Deviation & .37779 & .40430 & .34531 & .44251 & .26900 \\
\hline Minimum & 1.38 & 1.14 & 1.88 & 1.75 & 1.96 \\
\hline Maximum & 3.13 & 3.00 & 4.13 & 4.50 & 3.44 \\
\hline
\end{tabular}

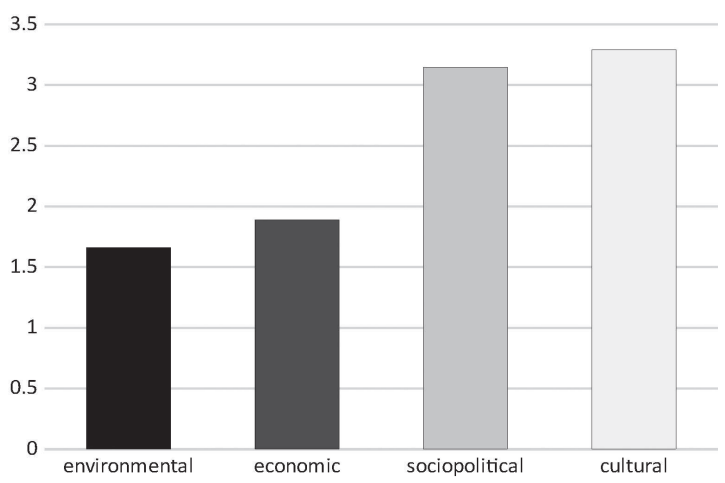

Figure 6. Means comparison of sustainability literacy dimensions 
Looking at the results of the descriptive statistics for sustainability implementation and its sub-divisions shown in Table 6 and Figure 7, certain differences between sustainability implementation dimensions can be found. Out of the four dimensions of sustainability implementation, the professional dimension is the first frequent one with the mean score of 3.42 and the curricular dimension is the last frequent one with the mean score of 2.82 among EFL instructors. The affective and ethical dimensions are the second (3.34) and third (3.09) frequent ones, respectively.

Table 6

Descriptive Statistics of the Participating Instructors' Sustainability Implementation

\begin{tabular}{lccccc}
\hline & curricular & professional & ethical & affective & s. implementation \\
\hline Mean & 2.8200 & 3.4218 & 3.0978 & 3.3438 & 3.2832 \\
\hline Std. Deviation & .36765 & .15474 & .25452 & .24777 & .11382 \\
\hline Minimum & 2.00 & 2.89 & 2.56 & 2.71 & 2.89 \\
\hline Maximum & 3.67 & 3.79 & 3.67 & 4.00 & 3.55 \\
\hline
\end{tabular}

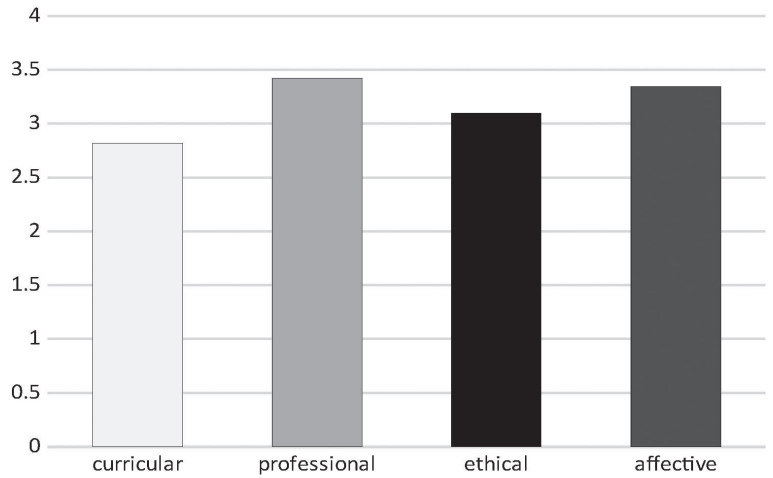

Figure 7. Means comparison of sustainability implementation dimensions

Table 7 shows the results of the status of sustainability education. The mean score (2.83) demonstrates that EFL instructors are not in a satisfactory position in terms of SE.

Table 7

Mean of Sustainability Education

\begin{tabular}{lc}
\hline Mean & 2.8385 \\
\hline Std. Deviation & .18362 \\
\hline Minimum & 2.05 \\
\hline Maximum & 3.66 \\
\hline
\end{tabular}

\section{One-Sample Kolmogorov-Smirnov Test}

To check the normality of the distribution, one-sample Kolmogorov-Smirnov test was used for sustainability literacy and implementation separately. The results are shown in Tables 8 and 9. 
As shown in Table 8, Asymp. sig for all the four dimensions and finally for sustainability literacy is over 0.05 , confirming the normality of the variables and allowing for the use of parametric tests for data analysis.

Table 8

One-Sample Kolmogorov-Smirnov Test for Sustainability Literacy

\begin{tabular}{lccccc}
\hline & environmental & economic & sociopolitical & cultural & s. literacy \\
\hline Test Statistic & .139 & .160 & .100 & .136 & .150 \\
\hline Asymp. Sig. (2-tailed) & .062 & .091 & .087 & .089 & .060 \\
\hline
\end{tabular}

As shown in Table 9, Asymp. sig for all the four dimensions and finally for sustainability implementation is above 0.05 , affirming the normality of the variables and allowing for the use of parametric tests for data analysis.

Table 9

One-Sample Kolmogorov-Smirnov Test for Sustainability Implementation

\begin{tabular}{lccccc}
\hline & curricular & professional & ethical & affective & s. implementation \\
\hline Test Statistic & .182 & .092 & .101 & .134 & .090 \\
\hline Asymp. Sig. (2-tailed) & .052 & .052 & .076 & .077 & .052 \\
\hline
\end{tabular}

The results of Kolmogorov-Smirnov test for SE are presented in Table 10 and the Asymp.sig value (0.60) affirms that the variables are normal and subsequently onesample t-test can be used.

Table 10

One-Sample Kolmogorov-Smirnov Test for Sustainability Education

\begin{tabular}{ll}
\hline Test Statistic & .197 \\
\hline Asymp. Sig. (2-tailed) & .602 \\
\hline
\end{tabular}

\section{One-Sample t-Test}

As the normality of the variables was affirmed in the previous section, a one-sample t-test was used to check if the mean differences noticed were significant. For this purpose, the t-test was run for sustainability literacy, sustainability implementation, and sustainability education.

According to Table 11, the hypothesis of the equality of the mean scores was rejected for all four dimensions. Considering the mean differences, the environmental and economic dimensions are proved to be below the medium $(-0.34$ and -0.10$)$, and sociopolitical and cultural dimensions are proved to be above the medium (0.14 and 0.29). The highest amount of the mean difference belongs to the cultural dimension and the lowest one belongs to the environmental dimension. 
Table 11

One-Sample t-Test for Sustainability Literacy Dimensions

\begin{tabular}{lcccccc}
\hline & \multirow{2}{*}{$\mathrm{t}$} & $\mathrm{df}$ & \multirow{2}{*}{$\begin{array}{c}\text { Sig. } \\
\text { (2-tailed) }\end{array}$} & $\begin{array}{c}\text { Mean } \\
\text { Difference }\end{array}$ & \multicolumn{2}{c}{$\begin{array}{c}95 \% \text { Confidence Interval } \\
\text { of the Difference }\end{array}$} \\
\cline { 6 - 7 } & & & & & Lower & Upper \\
\hline environmental & -43.364 & 149 & .000 & -1.33760 & -1.3986 & -1.2766 \\
\hline economic & -33.603 & 149 & .000 & -1.10927 & -1.1745 & -1.0440 \\
\hline sociopolitical & 5.268 & 149 & .000 & .14853 & .0928 & .2042 \\
\hline cultural & 8.072 & 149 & .000 & .29167 & .2203 & .3631 \\
\hline
\end{tabular}

The results of the one-sample t-test for sustainability implementation dimension, indicated in Table 12, show that the null hypothesis of the equality of the mean scores has been rejected for all the four dimensions. On the basis of the mean differences, it can be concluded that the curricular dimension has been the only dimension below the mean score $(-0.18)$ and the other dimensions are proved to be above the mean score $(0.42,0.09$, and 0.34$)$. The highest mean difference belongs to the professional dimension and the lowest one belongs to the curricular dimension.

Table 12

One-Sample t-Test for Sustainability Implementation Dimensions

\begin{tabular}{lcccccc}
\hline & \multirow{2}{*}{$\mathrm{t}$} & $\mathrm{df}$ & $\begin{array}{c}\text { Sig. } \\
(2 \text {-tailed })\end{array}$ & $\begin{array}{c}\text { Mean } \\
\text { Difference }\end{array}$ & \multicolumn{2}{c}{$\begin{array}{c}95 \text { \% Confidence Interval } \\
\text { of the Difference }\end{array}$} \\
\cline { 6 - 7 } & & & & & Lower & Upper \\
\hline curricular & -5.996 & 149 & .000 & -.18000 & -.2393 & -.1207 \\
\hline professional & 33.381 & 149 & .000 & .42175 & .3968 & .4467 \\
\hline ethical & 4.705 & 149 & .000 & .09778 & .0567 & .1388 \\
\hline affective & 16.995 & 149 & .000 & .34381 & .3038 & .3838 \\
\hline
\end{tabular}

The results of the one-sample t-test for sustainability literacy and implementation, shown in Table 13, confirm that sustainability literacy mean score is below the medium since the mean difference is equal to -0.59 and sustainability implementation mean score is above the medium since the mean difference is equal to 0.28 . The mean differences between the attained scores and medium (3) are significantly effective at 0.05 level.

Table 13

One-Sample t-Test for Sustainability Literacy and Implementation

\begin{tabular}{|c|c|c|c|c|c|c|}
\hline & \multirow[t]{2}{*}{$\mathrm{t}$} & \multirow[t]{2}{*}{$\mathrm{df}$} & \multirow{2}{*}{$\begin{array}{c}\text { Sig. } \\
(2 \text {-tailed })\end{array}$} & \multirow{2}{*}{$\begin{array}{c}\text { Mean } \\
\text { Difference }\end{array}$} & \multicolumn{2}{|c|}{$\begin{array}{c}95 \% \text { Confidence Interval } \\
\text { of the Difference }\end{array}$} \\
\hline & & & & & Lower & Upper \\
\hline s.literacy & -27.233 & 149 & .000 & -.59813 & -.6415 & -.5547 \\
\hline s.implementation & 30.469 & 149 & .000 & .28316 & .2648 & .3015 \\
\hline
\end{tabular}

As shown in Table 14, the results confirm that EFL instructors' SE level is significantly below the medium since the mean difference between the attained score and medium $(3)$ is equal to -0.16 . 
Table 14

One-Sample t-Test for Sustainability Education

\begin{tabular}{lcccccc}
\hline & & & \multirow{2}{*}{$\begin{array}{c}\text { Sig. } \\
\text { (2-tailed) }\end{array}$} & $\begin{array}{c}\text { Mean } \\
\text { Difference }\end{array}$ & \multicolumn{2}{c}{$\begin{array}{c}95 \text { Confidence Interval } \\
\text { of the Difference }\end{array}$} \\
\cline { 6 - 7 } & -11.198 & 161 & .000 & -.16154 & Lower & Upper \\
\hline dataall & & & & & &
\end{tabular}

\section{EFL SE Glocalized Model}

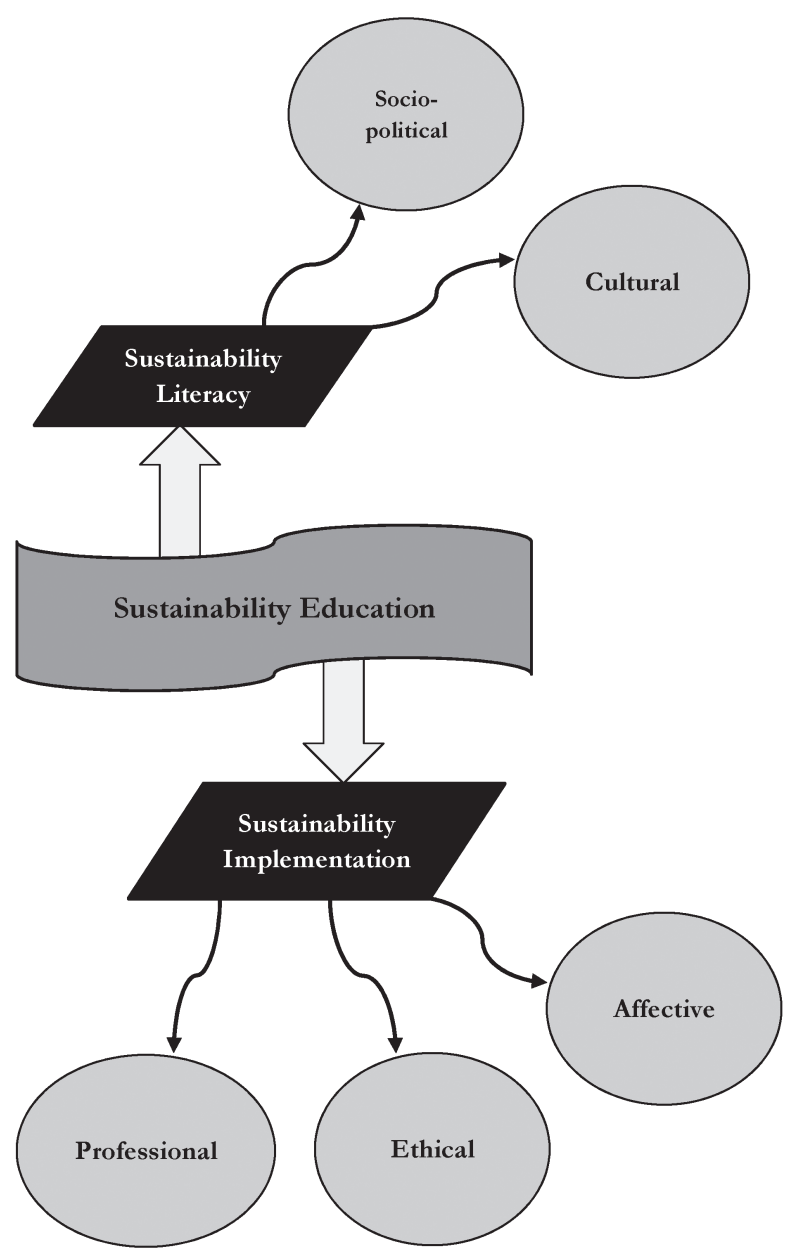

Figure 8. EFL SE glocalized model

A comparison of the EFL SE glocalized model (Figure 8) with the comprehensive model developed based on the literature reveals that the components of the glocalized model are not complete. This model reveals the EFL instructors' deficiencies in the realm of sustainability literacy and implementation. It shows that neither sustainability literacy nor sustainability implementation is complete among the Iranian EFL instructors. It also shows that the relation between the two phases of literacy and implementation 
has not been circular as opposed to the comprehensive model. The two phases have a linear relation since they have worked separately but not inter-connectedly.

\section{Discussion}

The aim of the present study has been to gain an insight into EFL instructors' sustainability literacy and implementation needs, and on that basis to suggest training courses for teacher education programs to turn EFL instructors into powerful SE agents who can help EFL learners become not only communicatively competent but also literate and conscious in sustainability. The following recommendations are proposed and discussed according to the results.

EFL instructors recorded below medium literacy in sustainability specifically in the environmental and economic dimensions: Preparing more sustainability literacy training for EFL instructors

Regarding the first and second research questions which were around EFL instructors' sustainability literacy, the findings of the study revealed that EFL instructors lacked Sustainability Literacy specifically in the environmental and economic dimensions. This lack of literacy can be at the first stage due to the instructors' unfamiliarity with technical terms and issues and, broadly speaking, a result of unfamiliarity with the whole idea of sustainability. In spite of the instructors' low scores in the environmental, economic and socio-political areas, they scored the highest in the cultural dimension, which affirmed the fact that EFL instructors were more conscious of cultural and cross-cultural issues. Additionally, the instructors' below the medium score is an indicator of the relationship between teachers' field of study and weaknesses as confirmed by Sund (2016). Environmental and economic issues are not dealt with in the field of TEFL. The mean score of instructors' sustainability literacy was 2.9, indicating that most EFL instructors were not literate in sustainability. As stated in some other studies, EFL teachers suffer from lack of confidence in teaching and preparing learners for the future since they do not have enough knowledge of SE (Summers, Childs, \& Corney, 2005; Uitto \& Saloranta, 2017). The finding of the study regarding EFL instructors' sustainability literacy is in contrast with that of Anyolo et al. (2018) which shows that it will be easy and feasible for instructors to become literate in sustainability since sustainability literacy has mainly to do with environmental and economic issues and these issues are spontaneously absorbed into the mainstream of teaching systems. The absorption of sustainability into teaching does have to do with the teachers' field of study. Yet, the first finding of the present study is in line with Dominici and Peruccio's eco-literacy shortage (2016). As stated previously, the need for the incorporation of eco-literacy into all levels of education, including higher education, was foregrounded by Dominici and Peruccio.

EFL instructors recorded a little above medium implementation in sustainability, specifically in the professional and affective dimensions: Preparing more curricular sustainability implementation training for EFL instructors

With regard to the third and fourth research questions which sought the frequency of sustainability implementation, EFL instructors recorded better results in comparison 
with sustainability literacy, which showed that they tried to actualize sustainability in their classes although they were not technically familiar with the whole idea. The instructors' above the mean scores in professional, affective and ethical dimensions affirmed their sensitivity towards professional core skills, attitudes and moral principles, which was in line with the judgment claiming that TEFL and SE were both holistic approaches regarding different aspects of implementation (Yavetz, Goldman, \& Pe'er, 2014). The instructors in Sund's study also paid attention to affective and professional dimensions. The only dimension about which EFL instructors did not seem willing to actualize was the curricular dimension. This shows that curriculum is not a priority from instructors' point of view. As pointed out previously, the instructors in Sund's and Anyolo's studies took careful account of curriculum development and modification as opposed to the instructors in the present study, which could be an indicator of the effect of the instructors' major. In other words, instructors may take power over specific aspects of sustainability based on their field of study. Another manifestation of this contrast is the relationship between sustainability literacy and curriculum planning as stated by Sund (2016). As a matter of fact, Iranian EFL instructors' neglect of curriculum can be akin to their sustainability literacy deprivation.

\section{EFL instructors recorded below medium in Sustainability Education: Preparing more Sustainability Education training for EFL instructors}

With respect to the fifth research question which was an attempt to unfold the state of SE among EFL instructors, EFL instructors' total score revealed that in spite of their strengths, they needed to be technically and academically trained in terms of Sustainability Education since the structural change, which was desired for the incorporation of SE into TEFL, would be not exclusively but primarily in the hands of instructors. In fact, universities, researchers and teacher educators should increase their sensitivity and awareness to help EFL instructors win over their shortcomings. This is exactly what was propounded by Frisk in 2011 and Stewart in 2010. This deficiency in TEFL departments is mainly due to insufficiency of teacher training and curriculum materials as stated in previous studies (Redman, 2013; Zeeshan, 2017). The finding rejects what was stated in Anyolo et al. (2018). In their study, it was claimed that teachers could reach the level of literacy and implementation without any training, preparation and familiarity with SE components which was not really the case in the present study. The EFL instructors' deficiencies can also be akin to their field of study as mentioned in previous studies (Andic \& Vorkapic, 2017; Anyolo et al., 2018; Sund, 2016).

\section{EFL SE model in Iran is not comprehensive: Some aspects of SE are neither known nor actualized}

Considering the last research question, the components of the EFL SE model in Iran are extracted based on the statistical results. The model confirms that the Iranian EFL instructors are far from ideal regarding SE. This represents that they need to undergo training in every aspect of SE, otherwise they will not be able to expand the learners' views toward sustainability issues and teach them how to take action or make changes against them. This model is in direct response to Zeeshan's study who was in search of the true type of information that should be incorporated into English classes through discussions, lectures, presentations, and videos. 


\section{Conclusions}

Regarding the history of EFL SE and the insufficiency of information in this area, this study shed light on different aspects of SE among EFL instructors, which could be crucial in EFL teacher education. The present study was an attempt to answer different questions in the area of SE and TEFL. In response to the first and second research questions, one can come to the point that EFL instructors are not competent regarding their sustainability literacy specifically in the environmental and economic dimensions. In response to the third and fourth questions, it is concluded that EFL instructors try to implement SE practices in their classes specifically the professional and affective dimensions; however, they have not been fully successful. And as a final point, all the evidence leads to the inescapable conclusion that EFL instructors are not educated in sustainability in spite of their merits. A close and detailed inspection of the results of the study reveals that teacher education programs and teacher educators must equip EFL instructors with SE proficiencies regarding both the literacy and implementation aspects. The training can move forward and capitalize on the instructors' strengths. EFL instructors have the potential to go from strength to strength provided that they become acutely aware of their weaknesses and know how to alter them. The results also will lead to the consideration of wider implications:

1) Sustainability and EFL are not unrelated: SE can be incorporated into TEFL; EFL instructors have not been totally unfamiliar with sustainability issues. The instructors' satisfactory level of socio-political and cultural literacy and professional, ethical, and effective implementation confirm that EFL and SE can be interwoven, as stated by Zeeshan (2017).

2) SE cannot come true without the instructors' both literacy and implementation; consciousness can lead to implementation and implementation can lead to consciousness.

3) Literacy and implementation should operate circularly: one should not be a prerequisite for the other, but they should positively affect each other. The results indicated that satisfactory performance in one phase, i.e., implementation, could not save the other phase, i.e., literacy, because EFL instructors viewed them as two separate phases operating linearly. Yet, SE needs a holistic view that considers the relation between the two phases as circular. This way, the weaknesses in one phase can turn to strengths with the help of the strengths in the other phase. The advantages of the instructors in some specific areas cannot turn them into successful SE agents.

4) Reaching a satisfactory level in all the dimensions of literacy and implementation is necessary for instructors.

On condition that teacher education programs do not provide EFL instructors with the necessary SE training courses, not only the quality of EFL classes but also the whole society will be affected since the implementation of SE in all subject areas of education including TEFL is considered to be a must (Uitto \& Solarants, 2017). As Burns stated in his Sustainability Model, Constructivism (Ernest, 1991; Philips, 1995; Vygotsky, 1962), Transformative Learning (Baumgartner, 2019; Mezirow, 1991), Critical Theory (Freire, 1970; Hooks, 2010), Place Based Learning (Orr, 2004; Sobel, 2005), Situated Experiential Learning (Fenwick), and Experiential Learning (Dewey, 1938; Kolb, 1984) are the building blocks of sustainability pedagogy and learning theories. 
Implementation of SE in language classes prompts critical thinking and critical thinking provokes better use of language strategies (Atkinson, 1997).

The positive effect of EFL SE implementation is two-folded: educational and social. From the point of view of learning quality, the results regarding the state of EFL SE in Iran can provide worthwhile information about the status of CLT in Iran since the competencies, perspectives, processes and strategies of EFL SE overlap, to a large extent, with those of CLT (Tsukamoto, 2014). A close look at the state of EFL SE in Iran can reveal the instructors' weaknesses, and the revelation of the weaknesses can tell teacher educators what should be incorporated into teacher education programs. When EFL instructors' weaknesses are turned into strengths, they can decide on the best topics which should be covered in English classes. This helps learners broaden their knowledge of communication and globalization and feeds into CLT actualization. From the point of view of teaching quality, EFL SE can affect teachers' professional development, professional responsibility, mindfulness, awareness of context and autonomy (Nolet, 2009). Getting familiar with SE paradigms in teacher education courses, university teachers will develop adaptive expertise (Bransford, Brown, \& Cocking, 2000). Moreover, from the point of view of life quality, being equipped with the knowledge of SE, EFL teachers can move toward a better professional future and can help learners live a better life in the future since TEFL is highly engaged with sustainability issues such as human rights, environmental defense, religious multiplicity, gender impartiality, sustainable worldwide economic growth, poverty alleviation, inhibition of conflicts between countries, eradication of weapons of mass destruction, charitable assistance, and preservation of cultural diversity. Teaching English helps learners find personal fulfillment and mutual understanding and a sense of global citizenship. It is remarkable that the sense of fulfillment, global citizenship and shared understanding are at the heart of SE. This represents that learning English, as the world's language, can deepen the learners' consideration of the world and, accordingly, their real understanding of national and international identities. These representations confirm how TEFL and SE are tied up.

\section{References}

Abdulwali, H. A., Alshmrani, S. M., \& Almufti, A. N. (2017). Secondary school science teachers' views about their reflective practices. Journal of Teacher Education for Sustainability, 19(1), 45-53.

Andic, D., \& Vorkapic, S.T. (2017). Teacher education for sustainability: The awareness and responsibility for sustainability problems. Journal of Teacher Education for Sustainability, 19(2), 121-137.

Anyolo, E. O., Karkkainen, S., \& Keinonen, T. (2018). Implementing education for sustainable development in Namibia: School teachers' perceptions and teaching practices. Journal of Teacher Education for Sustainability, 20(1), 64-81.

Atkinson D. (1997). A critical approach to critical thinking in TESOL. TESOL Quarterly, $31,71-94$.

Ban, K. (2012). Statement from the secretary-general. Retrieved from http://www.global educationfirst.org/289.htm

Basarir, F. (2017). Examining the perceptions of English instructors regarding the incorporation of Global Citizenship Education into ELT. International Journal of Languages' Education and Teaching, 5(4), 409-425. 
Baumgartner, L. M. (2019). Fostering transformative learning in educational settings. Adult Literacy Education, 1(1), 69-74.

Besong, F., \& Holland, C. (2015). The dispositions, abilities and behaviors (DAB) framework for profiling learners' sustainability competencies in higher education. Journal of Teacher Education for Sustainability, 17(1), 5-22.

Biasutti, M., De Baz, T., \& Alshawa, H. (2016). Assessing the infusion of sustainable principles into university curriculum. Journal of Teacher Education for Sustainability, 18(2), 21-40.

Bransford, J. D., Brown, A. L., \& Cocking, R. R. (2000). How people learn: Brain, mind, experience, and school. Washington, D.C.: National Academy Press.

Brundiers, K., \& Wiek, A. (2017). Beyond interpersonal competence: Teaching and learning professional skills in sustainability. Journal of Education Sciences, 7(39), 1-18.

Carban, E., \& Fisher, D. (2017). Sustainability reporting at schools: Challenges and benefits. Journal of Teacher Education for Sustainability, 19(1), 69-81.

Commission on the Development of Foreign Language Proficiency. (2011). Five proposals and specific measures for developing proficiency in English for international communication. Tokyo: Author.

Committee for Global Human Resources Development. (2012). Strategies for global human resources development. Tokyo: Author.

Corcoran, P. B., Osano, P. M., Weakland, J. P., \& Hollingshead, B. P. (2009). Young people, education, and sustainable development: Exploring principles, perspectives, and praxis. Wageningen, The Netherlands: Wageningen Academic Publishers.

Demirci, S., \& Teksoz, G. (2017). Self-efficacy beliefs on integrating sustainability into profession and daily life: In the words of university students. International Electronic Journal of Environmental Education, 7(2), 116-133.

Dewey, J. (1938). Experience and education. New York: Collier Books.

Dominici, L., \& Peruccio, P. P. (2016). Systemic education and awareness. The role of project-based-learning in the systemic view. Systems \& Design: Beyond Processes and Thinking, 302-314.

Ernest, P. (1991). Constructivism, the psychology of learning, and the nature of mathematics: Some critical issues. PME 15 Proceedings, 2, 25-32.

Fenwick, T. J. (2001). Experiential learning: A theoretical critique from five perspectives. ERIC Publications; Opinion Papers.

Freire, P. (1970). Pedagogy of the oppressed. New York: Continuum.

Frisk, E., \& Larson, K. (2011). Educating for sustainability: Competencies \& practices for transformative action. Journal of Sustainability Education, 2, 1-20.

Fry, C. L., \& Wei, C. A. (2015). Sustainability matters for undergraduate teaching and learning. Journal on Excellence in College Teaching, 26(3), 5-24.

Gholami, A., \& Qurbanzada, I. (2016). Key stakeholders' attitudes towards teacher education programs in TEFL: A case study of Farhangian University in Iran. Journal of Teacher Education for Sustainability, 18(2), 5-20.

Heasly, B., Iliško, Dz., Salìte, I., \& Lindner, J. (2020). The value of process and pedagogy through the sustainability prism. Discourse and Communication for Sustainable Education, 11(2), 1-4.

Hooks, b. (2010) Teaching critical thinking: Practical wisdom. New York: Routledge. 
Ishimori, H. (2010). Fostering global citizenship: High school students' conceptions of a global citizen. International Education, 16, 3-12.

Jacobs, G. M., \& Cates, K. (1999). Global education in second language teaching. KATA, 1(1), 44-56.

Kabadayi, A. (2016). A suggested in-service training model based on Turkish preschool Teachers' conceptions for sustainable development. Journal of Teacher Education for Sustainability, 18(1), 5-15. doi: 10.1515/jtes-2016-0001

Kolb, D. A. (1984). Experiential learning. Englewood Cliffs, NJ: Prentice-Hall.

Mezirow, J. (1991). Transformative dimensions of adult learning. San Francisco, CA: Jossey-Bass.

Nolet, V., (2009). Preparing sustainability-literate teachers. Teachers College Record, 3(2), 409-442.

Onwueme, I., \& Bosari, B. (2007). The sustainability asymptogram: A new philosophy framework for policy, outreach, and education in sustainability. International Journal of Sustainability in Higher Education, 8(1), 44-52.

Orr, D. W. (2004). Earth in mind: On education, environment, and the human prospect. Washington, DC: Earth Island Press.

Philips, D. C. (1995). The good, the bad, and the ugly: The many faces of constructivism. Educational Researcher, 24(7), 5-12.

Rashidi, N., \& Meihami, H. (2017). Addressing cultural identity through negotiation: Analysis of student-teacher-authored narratives. Journal of Teacher Education for Sustainability, 19(2), 21-35.

Redman, E. (2013). Opportunities and challenges for integrating sustainability education into K-12 schools: Case study Phoenix, AZ. Journal of Teacher Education for Sustainability, 15(2), 5-24.

Reunamo, J., \& Suomela, L. (2013). Education for sustainable development in early childhood education in Finland. Journal of Teacher Education for sustainability, 15(2), 91-102.

Samari, M. (2012). Sustainable development in Iran: A case study of implementation of sustainable factors in housing development in Iran. International Proceedings of Economics Development \& Research.

Sobel, D. (2005). Place-based education: Connecting classrooms and communities. Great Barrington, MA: The Orion Society.

Stewart, M. (2010). Transforming higher education: A practical plan for integrating sustainability education into the student experience. Journal of Sustainability Education, 1, 1-13.

Summers, M., Childs, A., \& Corney, G. (2005). Education for sustainable development in initial teacher training: Issues for interdisciplinary collaboration. Environmental Education Research, 11(5), 623-647.

Sund, L. (2016). Facing global sustainability issues: Teachers' experiences of their own practices in environmental and sustainability education. Environmental Education Research, 22(6), 788-805.

Tsukamoto, M. (2014). English language education for sustainable development: Fostering global citizenship. Bulletin of Southwest Jogakuin University, 18, 153-161.

Uitto, A., \& Saloranta, S. (2017). Subject teachers as educators for sustainability: A survey study. Education Sciences, 7(8), 1-19. 
Vincent, S., Bunn, S., \& Stevens, S. (2013). Sustainability education: Results from the 2012 census of U.S. four year colleges and universities national council for science and the environment council of environmental deans and directors. Washington DC: National Council for Science and the Environment.

Vygotsky, L. S. (1962). Thought and language. MIT Press, Massachusetts Institute of Technology and John Wiley and Sons.

Wals, A. E. J. (2011). Learning our way to sustainability. Journal of Education for Sustainable Development, 5(2), 177-186.

Wen, Y., \& Wu, J. (2017). A study on Singapore Chinese language teachers' professional proficiency and training needs for sustainable development. Journal of Teacher Education for Sustainability, 19(2), 69-89.

Yavetz, B., Goldman, D., \& Pe'er, S. (2014). How do preservice teachers perceive environment and its relevance to their area of teaching? Environmental Education Research, 20(3), 354-371.

Zeeshan, A. (2017). The necessity of teaching sustainable development through English language teaching. The IUP Journal of English Studies, 12(4), 95-103.

Correspondence concerning this paper should be addressed to Naser Rashidi, Department of Foreign Languages and Linguistics, College of Literature and Humanities, Shiraz University, Shiraz, Iran. Email: naser.rashidi@shirazu.ac.ir 